\title{
Do policy makers tell good stories? Towards a multi-layered framework for mapping and analysing policy narratives embracing futures
}

\author{
Michał Miedziński ${ }^{1}$ \\ Institute for Sustainable Resources, University College London
}

\begin{abstract}
Faced with major global problems, public policies increasingly embrace narratives of systemic transition towards desired future. This article introduces a conceptual and analytical framework designed to reconstruct and analyse historical and prospective policy discourses on emerging societal challenges. The proposed Policy Narrative Framework Analysis (POLiFRAME) is novel in integrating frame analysis with the notion of theory of change connecting historical and prospective dimensions of policy narratives. The framework adds an emphasis on the selection and interpretation of empirical evidence to support policy narratives. Application of the framework is illustrated with a case study on frames and reframing of EU resource efficiency policy.
\end{abstract}

Key words: policy narrative, frame analysis, theory of change, policy reframing, EU environmental policy

\section{Introduction}

Public policies face increasingly complex challenges requiring long-term systemic thinking and wide-ranging collaborations bridging diverse policy and professional communities. Building shared understanding of what are the direst societal problems, and what should be a common course of future action is a high-stake, and often contested, process. As in any negotiation process, stakeholders have different perspectives and frames of reference on seemingly the same issues. These differences may lead to misunderstandings and diverging proposals for future priorities, actions and investments. This paper argues that understanding how various policy actors frame and reframe past, present and emergent problems is fundamental for building shared visions and lasting policy coalitions.

The proposed policy narrative framework analysis (POLiFRAME) allows to map, critically analyse and compare policy frames emerging from policy narratives. The framework combines the dimension of policy narrative and layered discursive analysis with a dedicated focus on the use of evidence into one relatively simple conceptual framework and methodological approach.

\footnotetext{
${ }^{1}$ E-mail address: m.miedzinski@ucl.ac.uk; Address: UCL Institute for Sustainable Resources, Central House, 14 Upper Woburn Place, London WC1H ONN
} 
The value and novelty of POLiFRAME lies in combining concepts and analytical perspectives from different research traditions. The framework combines insights from policy analysis, organisational research, and futures studies. The understanding of policy narrative, frame and reframing in this paper builds on policy studies (Fischer and Forester, 1993; Schon and Rein, 1994; Fischer, 2003; Fischer et al., 2007; Fischer, 2012) and organisational learning research (Argyris and Schon, 1996; Wenger, 1998). The prospective dimension in the framework draws on futures studies and foresight, in particular causal layered analysis (CLA) (Inayatullah, 1998), post-normal science (Funtowicz and Ravetz, 1993) and foresight knowledge (Schomberg et al., 2005; Guimarães Pereira et al., 2007).

The framework can be used as an analytical tool in critical policy analysis and futures studies. POLiFRAME has been empirically tested in an in-depth empirical case study on frames and reframing of resource efficiency policy of the European Commission (Miedzinski, 2015). The framework could also assist scenario and vision building and other foresight exercises, for example, as a compliment to CLA or a critical companion of policy roadmapping processes.

The paper is structured into five sections. Section 2 provides background and introduces key concepts used to construct the framework. Section 3 introduces POLiFRAME. Section 4 applies the framework to the empirical case study. Section 5 concludes the paper with a discussion on key findings and possible research and policy applications of the framework.

\section{Background and key concepts}

The study of narratives is instrumental for policy discourse analysis (van Eeten, 2007). Policy narratives are socially constructed by policy stakeholders for specific purposes. They consist of stories, metaphors and arguments used to support a specific line of argumentation. Policy stakeholders construct narratives by blending empirical evidence with normative goals; the structure of policy arguments resembles 'a complex blend of factual statements, interpretations, opinions, and evaluations' (Majone, 1989).

Policy narratives consist of stories, arguments and metaphors making use of combinations of empirical evidence and normative claims. Narrative are the main unit of analysis used to analyse policy discourses. As a social construct shared by groups of actors and organisations they can be considered an 'aggregate unit of analysis' in policy research (Elkjaer, 2003). Hence, policy narratives can be analysed on different levels, ranging from individuals and groups to large organisations, groups of organisations, or even societies. For example, 'societal narratives' have been analysed by Dicke (2001). In this paper policy narratives are considered an intersubjective social construct.

Frame analysis was first introduced in sociological and psychological studies by Erving Goffman (Goffman, 1974) and linguistic and cognitive research notably by George Lakoff and Mark Johnson (Lakoff and Johnson, 1980). This paper draws on the understanding of frames applied in critical policy analysis, notably by Schön and Rein (1994). Schön and Rein (1994: 23) defined frames as 'structures of belief, perception, and appreciation that underlie policy positions'. They introduced the concept of frames and frame reflection as an alternative to the positivist policy analysis based on the rational model of policy making. They see policy process as 'dialectic, conversation and design' (ibid: 188) rather 
than mostly 'choice, politics and negotiation' (ibid: 37). Frames rest on the blend of prevailing systems of believes, metaphors and worldviews, knowledge and evidence of facts and trends, power relations as well as organisational culture of specific actors. They provide useful analytical lenses to interrogate policy narratives.

This study proposes to introduce the notion of future frames understood a structures and boundaries of belief, perception, and appreciation that underlie policy positions on emerging and future problems. Future frames complement policy frame analysis by introducing the notion of temporal frames and temporality to frame analysis. This analytical extension allows to reflect on how actors problematise expected, desired or feared futures in setting agenda and designing public policies.

Policy reframing is a process of policy frame change. This paper focuses on the instrumental (or intentional) reframing of policy considered an intentional act (or series of acts) aiming at changing dominant policy frames by policy actors. The study assumes that different policy actors frame and reframe problems differently in specific contexts. Frames depend on the relation of actors to the problem which can explain motivations and incentives behind advancing specific policy discourses. The study assumes that different policy actors intentionally attempt to reframe problems as a part of their engagement in policy process to advance their position on specific issues.

Frame reflection, with its structured approach to policy discourse analysis, allows for comprehensive comparisons between policy frames emerging in response to the same issue. The notion of discourse affinity is used to analyse similarities and differences of various elements of policy narratives. The reframing of policy may lead to alignment or divergence of different lines of argumentation brought forward by various stakeholders. Argumentative alignment focuses on changes of narratives by policy stakeholders enacted with an intention to align with other policy narratives and discourse coalitions (Hajer, 1993; Hajer and Wagenaar, 2003; Fischer, 2003).

\section{Introducing policy narrative framework analysis}

\subsection{Policy narrative framework}

The proposed policy narrative framework analysis (POLiFRAME) offers a systemic approach to analysing and constructing policy narratives with a focus on the notion of change and long-term transition. POLiFRAME provides a logical structure to reconstruct or construct policy narratives emerging from the testimonies of policy actors and formal policy documents.

The framework combines two analytic dimensions:

1. Storylines and argumentation: a structured enquiry into historical, present and prospective policy narratives constructed around a specific policy challenge and presented on a timeline; and

2. Narrative frame analysis: an in-depth layered analysis of policy frames, including the use and interpretation of facts and evidence, explicit and implicit causal inferences about social and economic processes in policy narratives as well as the underlying deeper normative and cognitive assumptions of policy frames. 


\subsection{Storyline and argumentation: towards a revealed theory of change}

The first dimension of the framework reconstructs the storyline and argumentation in policy narratives. It is about 'time frames of frames'. This component of POLiFEAME draws mainly on the interpretive approaches to policy analysis (Fischer and Forester, 1993; Schon and Rein, 1994; Fischer, 2003; Fischer et al., 2007; van Eeten, 2007; Fischer, 2012).

Storyline and argumentation are introduced as a structured narrative timeline (see Figure 1). The main building blocks of the timeline include: systemic deficiencies, first-order problems, scenarios of change and future vision. 'First-order problems' and 'systemic deficiencies' refer to the historical and present dimension (problem frames) whereas 'scenarios of change' and 'future vision' introduce the prospective dimensions of policy narratives (future frames).

The first-order problems are difficulties or issues directly experienced or currently considered most relevant by actors. For example, limited access or high prices of raw materials can be a problem for companies depending on materials in their production processes. They may be also referred as symptoms of deeper systemic problems.
Figure 1. Elements of storylines and argumentation in the policy narrative framework analysis

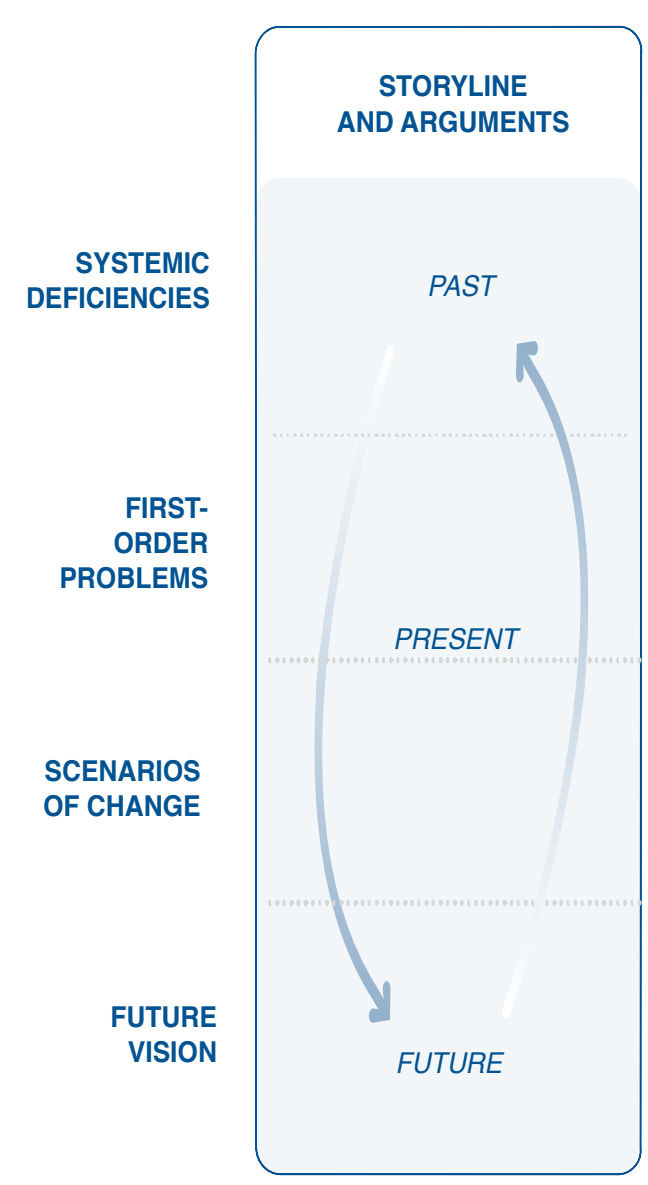

The underlying systemic deficiencies - or 'roots' of the problem - are what actors consider the main causes of first-order problems. For example, companies suffering from high prices of raw materials may believe the prices are caused by scarcity, inefficient extraction practices or by trade restrictions. Perceptions of what 'root problems' are is likely to differ between different actors: it can range from the focus on technological deficiencies to questioning deep beliefs underlying social and economic systems. Depending on the perceived problem boundaries and on how an issue is framed, what may appear to be a systemic deficiency for one stakeholder may appear to be just a symptom to another. The assumptions about how and why systemic deficiencies cause first-order problems are essential for understanding how problems are framed.

The identification of first-order problems and systemic deficiencies in policy narratives is often followed by suggestions of future changes (scenarios of change) leading to a desired future (vision). Analysis of how future-oriented elements of the narrative framework are understood can reveal differences between problem frames and future frames. Actors may have a generic or very concrete scenarios and visions of change depending on the directedness of their relationship with the issue at stake. The building blocks of the timeline are designed to reveal theories of change (causal assumptions) made in the 
policy narratives. They begin from the perceived historical roots of the policy problem and end with the future vision in which the problem is expected to be resolved or - if not addressed - lead to worsening of the current situation.

In reality policy narratives rarely form comprehensive and coherent storylines; by providing a simple modular structure to reconstruct policy narratives the framework allows for systemising policy narrative analysis. This is particularly relevant for policy narratives which take on complex long-term societal challenges. Adding an explicit future dimension to policy narrative opens up a new deliberative space where policy actors may find new alignments or diverge in their views.

\subsection{Narrative frame analysis}

Following the reconstruction of storylines and policy argumentation, the narrative enquiry continues with an in-depth narrative frame analysis that gradually build the depth of investigation of frames underlying policy narratives. The layered approach used in POLiFRAME is inspired by the CLA (Inayatullah, 1998). ${ }^{2}$ The layers in POLiFRAME were, however, designed to align with the timeline of policy narrative, and to address questions concerning the use of empirical evidence in the future-oriented policy narratives.

The analytical layers of POLiFRAME comprise:

- Facts and evidence in narratives: selection, use and interpretation of facts, empirical evidence as well as anticipated events and trends in the narrative;

- Causal assumptions in storylines: explicit and implicit assumptions on causal relations and systemic dependencies in the narratives;

- Underlying cognitive and normative determinants of narratives: interpretation of cognitive and normative determinants underlying frames used in the narrative.

The first analytical layer - facts and evidence - involves facts and evidence used by stakeholders to support their storylines and arguments. Depending on the policy process and stakeholders, these can range from scientific studies, expert knowledge, anecdotal evidence to, although rarely, an absence of empirical evidence. The framework introduces an explicit differentiation between evidence used by stakeholders to support the historical and prospective dimensions of policy narratives.

Following the mapping, the focus of analysis is on how information and knowledge is selected, used and interpreted to become an evidence base supporting policy argumentation. This focus follows Fischer's policy epistemics that focus on 'investigating the way interpretive judgements work in the production and distribution of knowledge' (Fischer, 2009). The notion of specific nature of knowledge used to support policies tackling complex and uncertain futures draws on the concepts of post-normal science (Funtowicz and Ravetz, 1993) and foresight knowledge (Schomberg et al., 2005; Guimarães Pereira et al., 2007).

The second layer focuses on causal assumptions in policy narratives, which could be seen as depicting theory of change underlying the storylines. The layer aims at identifying and

\footnotetext{
2 The CLA practitioners may find similarities between POLiFRAME and CLA. 'Storyline and arguments' in POLiFRAME is similar to 'litany' in CLA while the POLIFRAME's 'facts and evidence' and 'causality assumptions' can be considered 'social system' in CLA. The layer on 'normative and cognitive determinant' in POLiFRAME can be seen as an equivalent of 'worldview' and 'metaphor or myth' layers in the CLA.
} 
analysing explicit and implicit causal inferences in policy narratives. The emphasis on causal inferences in narratives relates to Argyris and Schön's (1996) 'situated causal enquiry' used to map and verify the cause-effect assumptions in theories of change used by social actors. The analysis may reveal logical inconsistencies and leaps or vague statements on causal relations.

The third layer is a deep dive into normative and cognitive determinants underlying policy narratives. The interpretive effort focuses on exploring normative motivations and interests, values, beliefs, metaphors and ideologies or even myths that explicitly or implicitly underlie assumptions and choices made in policy narratives. The latter includes a reflection on deeply rooted assumptions and metaphors about 'underlying structures', systemic dependencies and mechanisms that allow one to understand how and why different actors perceive and draw different boundaries of the problem.

The third layer builds on concepts and insights from interpretive policy analysis (Schon and Rein, 1994; Fischer, 2003; Fischer, 2009), critical futures studies (Inayatullah, 1998) as well as organisational learning (Argyris and Schon, 1996; Wenger, 1998). The third layer is designed to support analysis of institutional and meta-cultural frames of policy discourse (Schon and Rein, 1994), and to delve in the dimension of ideology, power and persuasion underlying policy narratives (Majone, 1989; Fischer, 2003; van Eeten, 2007). The lessons from organisational learning research are relevant here as they explore cognitive and cultural determinants of social learning and organisational change (Argyris and Schon, 1996; Wenger, 1998).

This deeper discursive layer is also a space where metaphors evoked in policy narratives can be analysed and interpreted as important cognitive and normative determinants underpinning policy frames. The latter can benefit from the recent research published in this journal (Inayatullah et al., 2016; Judge, 2016; Vallis and Inayatullah, 2016; Carbonell et al., 2016) and draw on the seminal research on metaphors and cognition by Lakoff and Johnson (Lakoff and Johnson, 1980).

The framework proposed in this paper aims to add new dimensions and questions of particular relevance to policy analysis. The main novelty of POLiFRAME compared to CLA lies in connecting layered analysis with the notion of theory of change represented as a structured storyline of the policy narrative. The explicit distinction between temporal dimensions of policy narrative allows for historical and prospective tracing of policy narratives. The reconstructed storylines held by different actors are then a basis for an analysis of assumptions and worldviews that underpin historical interpretations and future scenarios and visions. This allows to ask questions on whether and to what extent adding a prospective dimension to the policy narrative changes the frames of reference on the same problem (e.g. if the problem is likely to become more serious in the future, its present relevance may be expected to increase). Further, the incoherence between historical evidence and future scenarios may reveal deeply held beliefs of actors which are persistent even in the face of new evidence on emerging problems.

Figure 2 introduces the main components of the policy narrative framework analysis combining the storyline and argumentation with analytical layers of the framework. Figure 3 presents an annotated matrix with the analytical dimensions of the analysis. The matrix is designed to map, analyse and compare policy narratives. 
Figure 2. Introducing the policy narrative framework analysis (POLiFRAME)

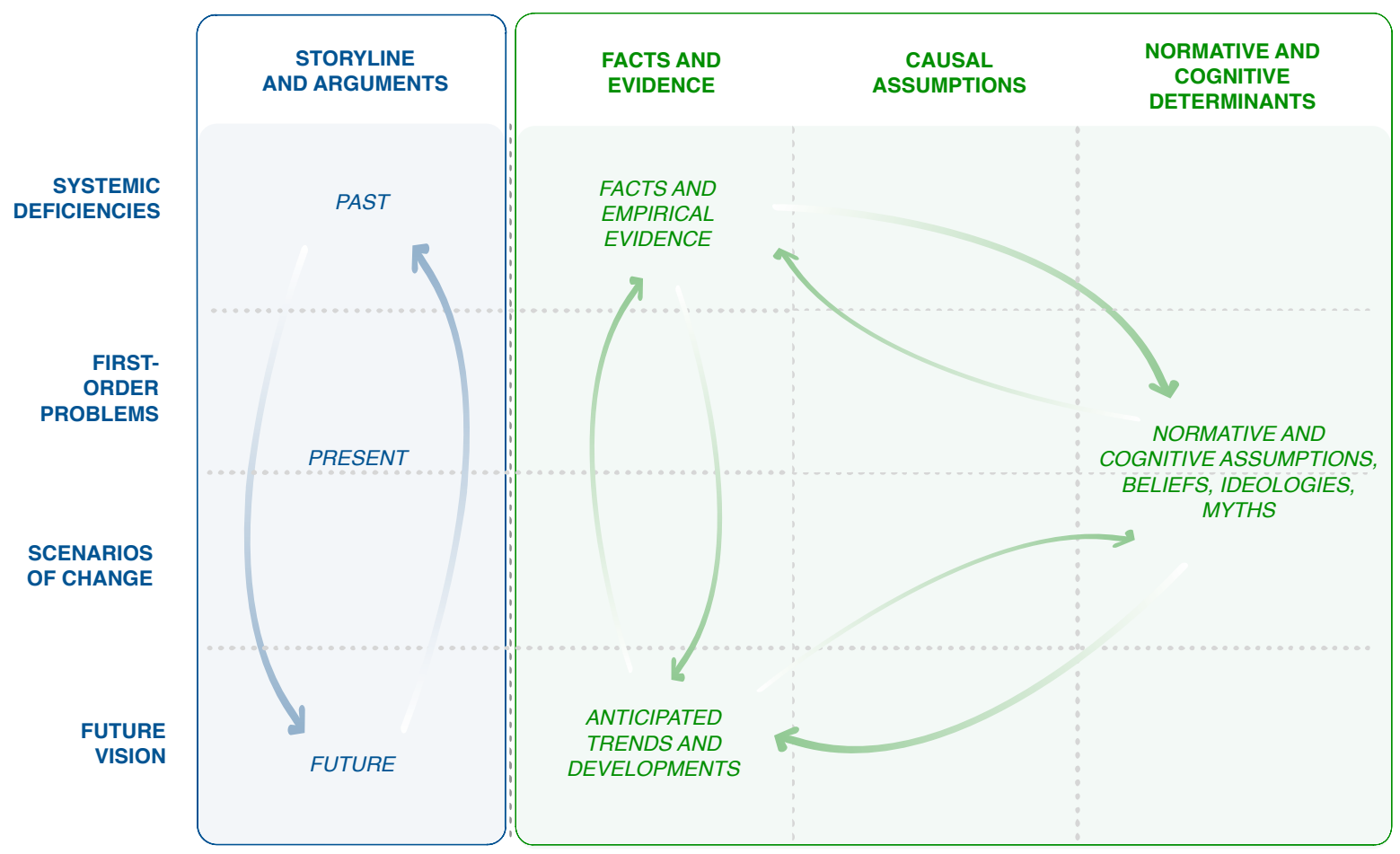

Figure 3. Analysing policy narratives and frames with POLiFRAME

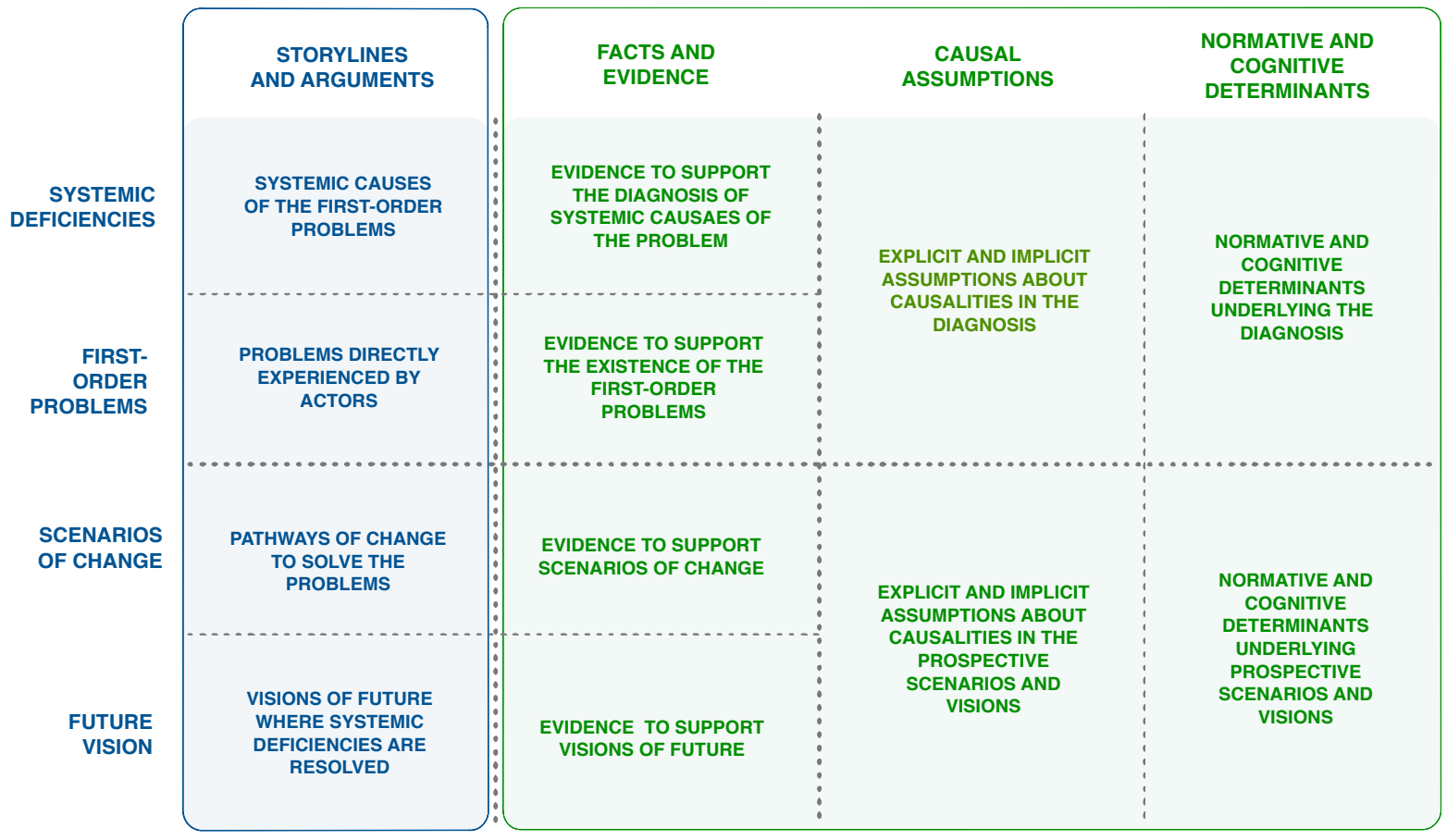




\subsection{Facts and evidence in policy narrative: an interpretive approach}

Understanding policy frames underpinning policy narratives is essential for analysing processes and mechanisms of selection, interpretation and 'translation' of evidence into policy argumentation. The process of 'naming and framing' evidence is key as it allows to make "the 'normative leap' from data to recommendations, from fact to values, from 'is' to 'ought" (Schön and Rein 1994: 26). POLiFRAME is designed to, first, comprehensively map facts and empirical evidence used to support policy narratives, distinguishing between historical and prospective dimension of policy narratives. This mapping provides a basis for the critical analysis of the use of evidence to support causal claims in policy narratives. The second step comprises an in-depth analysis of the process of selection and interpretation of evidence, facts and indicators, used to support policy narratives put forward by different policy stakeholders.

What distinguishes POLiFRAME from other policy narrative approaches is a dedicated reflection on how existing evidence is 'translated' to support future scenarios and visions. The 'translation' can be range from quantitative model-based scenarios to running normative participatory processes of vision building. Building on the notion of foresight knowledge (Schomberg et al., 2005; Guimarães Pereira et al., 2007) and post-normal science (Funtowicz and Ravetz, 1993), POLiFRAME proposes the interpretation of knowledge and expertise used to inform policy may differ depending on the time horizon of policy narrative. In the long-term policies including a normative vision, the nature, use and interpretation of evidence may be different due to the normative nature of the vision as well as due to the inherent uncertainty of future. The construction of empirical evidence to support future policy vision is a deliberative process combining interpretations of empirical evidence, normative ramifications (including beliefs, vested interests, and power relations) as well as imagination and creativity used to construct anticipated and desired futures.

Finally, the framework allows to conduct an analysis on why and how the selection, use and interpretation of empirical evidence may change over time, notably at the time of policy reframing. The case study in this paper, for example, asks about the role of evidence in constructing new frames of EU policy on resource efficiency following an adoption of an ambitious strategy embracing long-term societal challenges.

The direction of relations between policy and evidence should not to be considered as a one-way linear process in which knowledge is 'translated' into evidence which in turn informs policy design. Evidence may be selected and interpreted (or 'translated') for the policy use differently depending on the policy goals and the wider political context. An interpretive policy analysis approach suggests that this process involves normative interpretation, in a sense that evidence base is constructed to inform policy decisions supporting normatively-charged political choices. As Stirling suggested: 'even in the most technical and sophisticated forms of analysis, it seems that the answer you get depends on the way you frame the question' (Stirling 1997).

Figure 4 depicts the policy-evidence interface in POLiFRAME as a deliberative space with non-linear iterative processes in which evidence influences policy narrative while, at the same time, normative goals and beliefs influence the process of selection, interpretation and validation of the evidence base. Policy narrative emerges from this as a blend of empirical evidence and normative goals (Majone, 1989). 
Figure 4. Facts and evidence in POLiFRAME

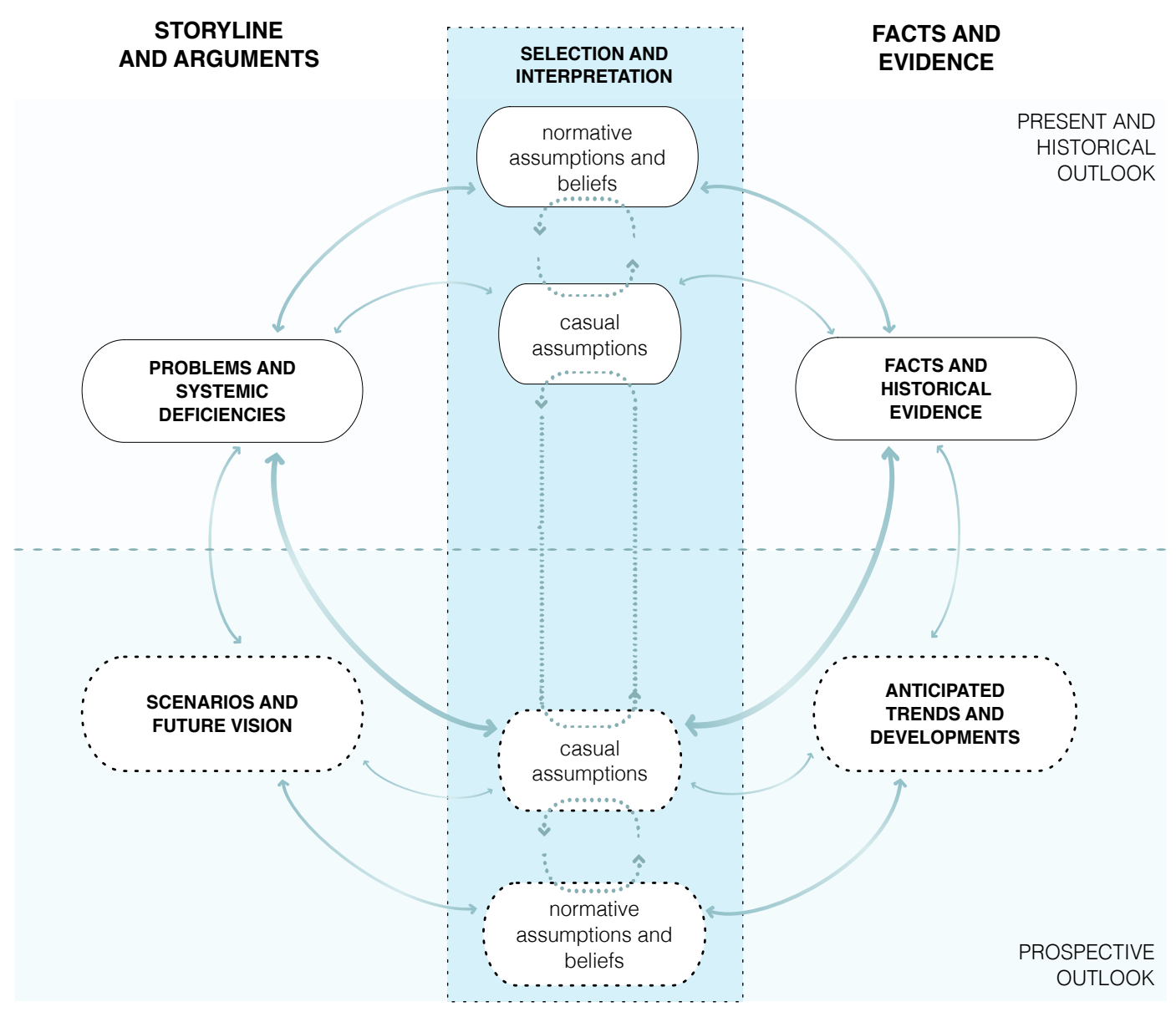

\subsection{Policy reframing}

The reframing of policy in this approach refers to the instrumental or intentional reframing of policy in which the reframing is an intended action of policy makers or other policy agents. The analysis of policy reframing may reveal different degrees of reconfigurations in policy narratives ranging from minor changes in the established storylines to radical shifts in problem frames underpinning policy narrative.

To assess the differences between old and new frames, the analysis of policy reframing will most often rely on a comparison between subsequent policy strategies setting up new strategic frameworks and policy goals for a policy area. The new frames are often first introduced in political speeches or white papers to be later confirmed in formal policy strategies and decisions.

Figure 5 illustrates narrative areas and discursive layers in which changes in policy frames can be investigated. 
Figure 5. Analysing the reframing of policy using POLiFRAME

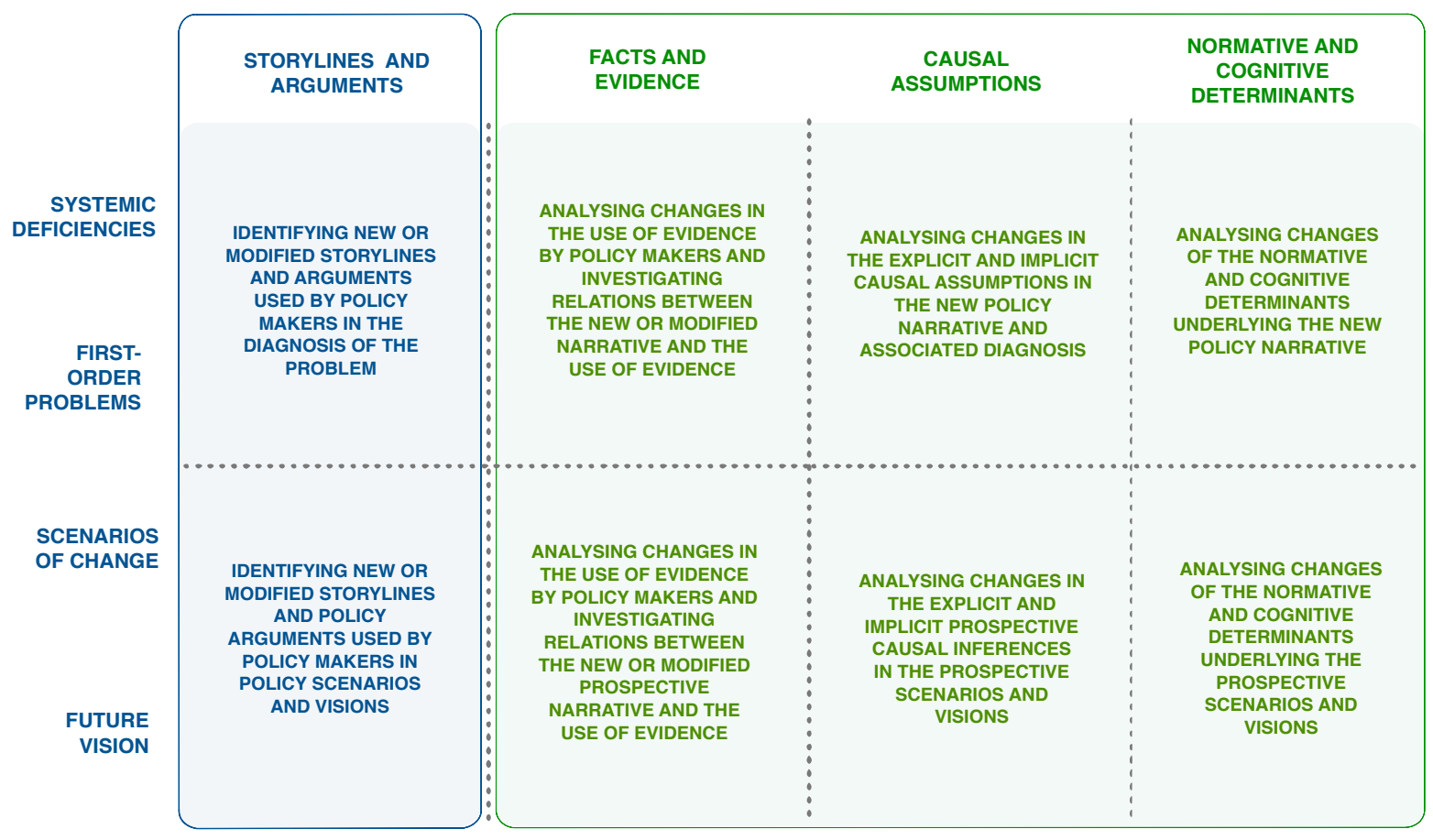

\section{Case study: analysing resource efficiency policy narrative in EU}

This chapter illustrates how POLiFRAME can be used in policy analysis. The case study consists of five parts. First, I introduce research design and methodology of the case study. Second, I analyse the policy narrative framework of the EC's 'Roadmap to a Resource Efficient Europe'(CEC 2011), referred to as 'the Roadmap' henceforth. Third, I analyse internal and external coherence of the Roadmap's narrative. Fourth, I discuss the reframing of resource efficiency policy by comparing the Roadmap to the EU Thematic Strategy (CEC 2005). Last but not least, I reflect on the wider context and emerging implications of policy reframing. This study is provided as an illustration of the use of POLiFRAME. The extended version of the case study can be consulted in Miedzinski (2015).

\subsection{Research design and methodology}

The case study was situated in a specific context of the EC policy process. Since addressing long-term societal challenges is relevant for any public policy organisation, the findings and reflections on the reframing of policy, and its implications for the use of evidence, are relevant to any policy maker or researcher concerned with the public policy's response to the future problems. This research can be considered a critical case study with 'strategic importance in relation to the general problem' (Flyvbjerg 2001: 78).

The purpose of case study was to gain a better understanding on how public policy narratives embrace long-term societal challenges. The EU resource efficiency policy, and the EC's 'Roadmap to a Resource Efficient Europe' in particular, was selected as a policy area explicitly tasked with addressing one of the 'grand societal challenges' brought up 
the Europe 2020 strategy (CEC, 2010). The narrative layers of POLiFRAME were adapted to reflect the problem area of the case, that is 'resource efficiency':

- First-order problems: what are the current problems linked to the use of natural resources (e.g. prices of commodities, environmental problems)?

- Systemic deficiencies: what are the 'roots' or systemic deficiencies underlying these problems (e.g. economic system, inappropriate technology)?

- Scenarios of change: what are the solutions and strategic actions to overcome problems and systemic deficiencies of resource efficiency? (e.g. technological innovation, new business models, regulatory intervention);

- Future vision: how should humankind approach natural resources in the future? (e.g. changing basic relationships, new technologies).

The case study was based on primary and secondary data. The empirical enquiry comprised a series of semi-structured interviews with 42 stakeholders involved in the EU research efficiency debate and public consultations. The selection of respondents was based on a purposeful sampling technique. The respondents included policy makers (EC and national policy makers), politicians (members of the European Parliament), business and EU level business associations, experts and researchers, NGOs as well as international organisations. The fieldwork was complimented by participation in the policy events on resource efficiency in 2012 and 2013. Desk research drew on formal policy documents, political speeches, technical reports, position papers as well as academic literature.

The interview questions were directly linked with the conceptual framework. They were adapted to the specific context of the interview (e.g. type of the stakeholder, duration of the interview etc.). All respondents received a two-page brief about the research along with the invitation. The interviews had been conducted in May-December 2012, of which majority took place in May-June 2012 in Brussels. The interview notes were validated by stakeholders. The interview notes were structurally coded in order to prepare thematically organised excerpts. The codes were set up to cover main research questions data requirements of POLiFRAME. The process of coding and excerpting was aided by the online software Dedoose (www.dedoose.com). This allowed for exporting excerpts organised by topic and descriptor data (i.e. key words, type of stakeholders). The views expressed in the interviews were not attributed to individuals or organisations if the latter can reveal the identity of the respondent. References to interview material in the case study are indicated as 'Stakeholder interview 2012'. The detailed referencing to empirical material can be found in Miedzinski (2015).

\subsection{Policy narrative framework of the Roadmap}

\subsubsection{Historical developments of $E U$ resource efficiency agenda}

The 'Roadmap to a Resource Efficient Europe' was published in September 2011. The political process preparing the ground for 'resource efficiency' as one of the key EU policy objectives should be, however, seen in the context of previous policy developments. 'Resource efficiency' was mentioned the 2001 European Gothenburg Council declaration on 'A Sustainable Europe for a better world: A European Strategy for Sustainable Development', in which the Council argued for decoupling of economic growth from the use of natural resources. The $6^{\text {th }}$ Environmental Action Programme (6EAP) later included 
resource efficiency as one of its priority areas. The agenda was elaborated in 'Thematic Strategy on the Sustainable Use of Natural Resources' (CEC, 2005).

Resource efficiency was reintroduced with a new vigour in 2010 by the EU 2020 strategy that made it one of its priorities. In January 2011, the EC put forward a 'Flagship Initiative for a Resource Efficient Europe' (CEC, 2011b). Flagship's main objective was 'to decouple (...) economic growth from resource and energy use, reduce $\mathrm{CO} 2$ emissions, enhance competitiveness and promote greater energy security' (CEC, 2011b). The document itself by large repeats the high-level objectives of the 6EAP and the 2005 Thematic Strategy by arguing that decoupling the use resources and environmental impact from economic growth has environmental and economic benefits (CEC, 2011a).

The Flagship was further elaborated by four 'coordinated roadmaps', including 'Roadmap to a Resource Efficient Europe'. The following sections analyse key components of the policy narrative of the Roadmap. Figure 6 introduces a summary POLiFRAME matrix. An extended version of the matrix is in Appendix $A$ (see supplementary material).

\subsubsection{First-order problems and systemic deficiencies}

The language of the Communication was strongly flavoured by the Europe 2020 rhetoric putting economic growth at the heart of the discourse. The dominant first-order problems in the Roadmap are economic concerns about rising costs of raw materials and volatile prices of materials, and material scarcity and import dependence on imported materials. Dependence on imports of resource is framed as a threat for EU economy, which reveals a predominantly euro-centric perspective and an underlying assumption of the world governed by competitiveness and struggle for dominance and survival. Environmental problems also feature prominently in the document. The Roadmap, however, most often frames environmental problems as an economic opportunity or threat; the loss of biodiversity, depletion of eco-system services, and pollution are all given a 'price tag'. The text stresses, for example, that resource efficiency is not only to decrease impacts of economy on environment, but also to understand and avoid 'systemic risks to the economy from the environment' (CEC, 2011a).

Systemic deficiencies are also predominantly economic. The root of the problem was that the current market economy fails to ensure prices that reflect the external cost of the resources. Market failure is at the core of the policy narrative pointing to wrong pricing signals and information asymmetries as a systemic deficiency: 'economic system still encourages the inefficient use of resources by pricing some below true costs' (CEC 2011). Importantly, the Roadmap indicated the wrong market signals are largely due to a systemic policy failure. The existing policy framework sends out wrong signals and incentives to the market that are exacerbating the problem. These 'wrong' price signals are 'deliberately' caused by policy, notably by environmentally harmful subsidies.

In the Roadmap's discourse nature is framed mainly as 'natural capital', which largely reduces it to an economically exploitable factor. Nature is seen primarily as a provider of goods and services. This reveals a normative assumption that humankind has a right to exploit nature to achieve growth and high standard of life. While the narrative is strong about the need to protect nature, the main reason to do is economic. The central argumentative proposition of the Roadmap's narrative is to revisit the notion of economic growth by recognising economic value of resources. The document argues for attributing 
'right' economic value not only to tradable commodities but also to non-tradable ecosystem services and resources such as water, land, air and biodiversity. The inclusions of nature at the core of the narrative is, however, done within economic frames that rely on a conventional understanding of economic value, often expressed with a price tag.

The Roadmap's narrative on environmental dimension, notably environmental limits and scarcities, is ambiguous. On the one hand, the document recognises the concept of 'planetary boundaries and resource constraints'. The document refers to 'safe operating space' (Rockström et al., 2009) and makes strong statements about recognising sustainable limits in its vision. The Roadmap may be seen as an attempt to change the policy discourse on the limits to growth, at least in the context of some resources, especially eco-system services, land and water. However, the document remains ambiguous on limits when referring to raw materials and other commodities, such as minerals, metals and other materials. This suggests that the question of 'limits' remains contentious, especially when it is perceived as a possible constraint of economic activity.

There is a logical tension between calling for 'recognising planetary limits and constraints' and relying on market-based mechanisms to correct decisions on the use and substitution of natural resources. The outspoken support for monetising all natural resources and almost exclusive focus on 'economic value' in the document can be considered a fundamental problem from the strong sustainability point of view. Monetising may be de facto permission to consider nature substitutable, which would make the limits negotiable and open to constant redefinition. The overall call for monetising natural capital and 'getting the prices right' does not substitute taking a firm stance on nature protection.

The Roadmap does not question fundamental values underlying the hierarchical relationship between humankind and nature. Value systems and lifestyles governing producer and consumer (and social) choices and practices are not fully explored. The Roadmap does not openly question the levels of final consumption. It focuses mainly on the production system. The Roadmap is based on assumption that remodelling economic system will suffice to lead to radical change, and should not decrease the standard of life. Many interviewed stakeholders emphasised that there was a lack of reflection and actions addressing the consumption side. The EC officials were well aware of the importance of consumption but they regarded it as too politically sensitive to challenge consumption patterns in the document. An implicit political message was that resource efficiency should not compromise consumer choices.

\subsubsection{Future vision and scenarios of change}

The Roadmap introduces a vision for 2050 and milestones for 2020. The vision states:

'By 2050 the EU's economy has grown in a way that respects resource constraints and planetary boundaries, thus contributing to global economic transformation. Our economy is competitive, inclusive and provides a high standard of living with much lower environmental impacts. All resources are sustainably managed, from raw materials to energy, water, air, land and soil. Climate change milestones have been reached, while biodiversity and the ecosystem services it underpins have been protected, valued and substantially restored.' (CEC, 2011a) 
The vision appears to have a stronger stance about the need to protect nature and recognise planetary limits then the problem analysis. The analysis of future frames, however, confirm the dominant economic argumentation. The vision is based on an assumption of rational behaviour of both economic actors and consumers who are expected to respond to newly provided signals and incentives to change their resource consumption. It has a mechanistic and linear perception of societal change based on an assumption that the transition can be prepared in 'a timely, predictable and controlled manner' (CEC, 2011a).

Creativity, innovation and entrepreneurial potential are to be directed and channelled to serve the vision. There is a belief, for example, that the entrepreneurial potential that has led to improved labour productivity 'over centuries' can be employed to drive innovation in resource efficiency. This reasoning is an example of interpreting and transposing historical evidence to support the vision. Entrepreneurial potential that worked in the past is expected to work again in the future. A related assumption is that the current economic and social model is capable to support a major societal learning process leading to economic transition, radically changed consumer behaviour and wider understanding of planetary boundaries.

The Roadmap avoids explicit statements on complexities, institutional lock-ins and uncertainties linked to any societal transition processes. There is only a limited reflection on systemic barriers to reconfiguring existing practices, networks and power relations. The Roadmap hints that the transition can create winners and losers, and the caution is called for when abolishing environmentally harmful subsidies. The notion of persistent 'lock-in' is mentioned in the context of discontinuing harmful subsidies but it is not elaborated and reflected in the other contexts. The approach to innovation and its role in transition is based on the linear understanding of innovation process in which progress takes place as a result of scientific breakthroughs. The reflection on the societal, cultural or institutional factors that drive or hamper innovation is absent from the document.

Despite considering the notion of incentives central to the process of economic change, the vision fails to consider incentives for those who are expected to introduce major changes in policy, namely politicians and policy makers themselves. The lack of political dimension of the transition is the major gap in the narrative framework of the Roadmap. This reflects the main focus on economic side of the narrative. It also reveals the actual and perceived role of the EC and the European Union in this process. Many political and policy drivers of transition (e.g. fiscal policies) remain in hands of national governments.

The causal inferences in the Roadmap's narrative on social change are predominantly linear. Orchestrated policy intervention is expected to play a key role in the transition by resetting the framework conditions to provide 'right' price signals and fiscal incentives for business and consumers. As a result, business is supposed to innovate while consumers are expected to change their behaviour. This reveals a deep belief in humankind's capacity to design and control its fate. Humankind can 'orchestrate' the planet (e.g. by adopting crops). The narrative does not reflect on non-economic determinants of consumption and production and on the inherent 'design uncertainty' of any major societal transformation. This mechanistic perception of social change is at odds with lessons from social science research, notably science and technology studies, evolutionary economy, social learning and organisational change or social psychology. 
The Roadmap's vision does not ponder about the transition's implications for social system and welfare. Despite calling for radical transformation, the vision seems to be striving for resetting of the parameters of the existing economic and social system. The implicit assumption is that the future society would be organised in a similar way as today.

\subsection{Facts and evidence in the Roadmap}

On the one hand, the case study demonstrated that the reframing of policy had an influence on both selection and 'translation' of evidence to support the formal policy argumentation. The reframing of policy shifted the discourse on resource efficiency towards economic benefits and risks. Looking for new ways to engage economic actors in environmental agenda was perceived as the way to keep the environmental policy among the priority strategic fields in the post-crisis times. Environmental policy had to be perceived to have an economic rationale and a sound 'business case'. Following reframing, policy stakeholders searched for and selected evidence in support of the new policy argumentation, notably supporting the 'business case' of resource efficiency. Selection and interpretation of evidence to support this frame was deliberate (Stakeholder interviews 2012).

On the other hand, the case study found instances in which new research findings had directly influenced the scope and the prioritisation within the policy area. This was the case of indicating most resource intensive sectors as well as indicating specific areas of concern such as food waste.

In general, the relations between changes of policy argumentation and available evidence were iterative and, one can say, dialectical. The fieldwork suggests that early evidence on economic benefits of resource efficiency and the warning messages on the dependence of Europe on resource imports were key in shifting resource efficiency up the political agenda prior to adopting EU 2020 Strategy. This evidence was then simplified and absorbed in the high-level policy argumentation of the Strategy. This in turn triggered off further search for suitable evidence supporting the new official line of argumentation.

The case study found that adding a future dimension to the policy debate uncovered gaps in evidence and knowledge, and revealed stark differences in understanding what constitutes 'sufficient evidence' to support future policy choices. The significance of the knowledge gap was perceived to have different implications by different stakeholders. The EC officials perceived resource efficiency as a field with a relatively weak evidence base, especially compared to climate change.

Uncertainty and the perceived lack of wide agreement among scientists and experts were interpreted as a weakness. One of the officials used a metaphor of compensation in which normative arguments and persuasion had to appear in the debate because of the lack of facts and uncontroversial scientific body of knowledge on resource efficiency. Uncertainty about future in this reasoning meant 'more normative arguments'. This suggests that the prospective dimension of policy narrative incudes the structure of arguments, and how they 'blend' empirical evidence and normative standpoints. 
Figure 6. Policy narrative framework analysis of the EC 'Roadmap to a Resource Efficient Europe'

\begin{tabular}{|c|c|c|c|c|c|}
\hline & & Storylines and arguments & Facts and evidence & Causal assumptions & Normative and cognitive assumptions \\
\hline 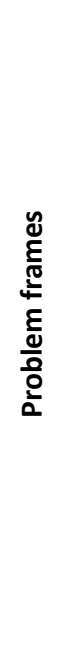 & $\begin{array}{l}\text { Systemic } \\
\text { deficiencies } \\
\text { (root } \\
\text { problems) }\end{array}$ & $\begin{array}{l}\text { High prices of resources } \\
\text { Environmental impacts } \\
\text { Excessive consumption resulting in food } \\
\text { waste and unsustainable land use }\end{array}$ & $\begin{array}{l}\text { Historical evidence on the relative increase } \\
\text { of consumption of fossil fuels and materials } \\
\text { Material consumption per capita per year } \\
\text { (including data on wasted materials) } \\
\text { Subsidies with potential negative impacts on } \\
\text { the environment } \\
\text { Economic cost of environmental } \\
\text { degradation (e.g. number of working days } \\
\text { lost due to air pollution induced illnesses) } \\
\text { State of ecosystems and environmental } \\
\text { degradation } \\
\text { Impact of pollution on human health } \\
\text { Waste generation and environmental } \\
\text { impacts of waste } \\
\text { Impacts on GHG emissions }\end{array}$ & $\begin{array}{l}\text { Difficult access to resources decreases } \\
\text { competitiveness of the EU } \\
\text { Current economic model generates } \\
\text { environmental pressures } \\
\text { Possible impacts on third countries due to } \\
\text { risks of resource access. }\end{array}$ & $\begin{array}{l}\text { Hierarchical relation in which humankind exploits } \\
\text { nature to achieve prosperity and wellbeing. } \\
\text { Nature framed as natural capital symbolically reducing } \\
\text { it to economically exploitable factor. Nature as a } \\
\text { provider of goods and services. } \\
\text { Environmental problems often framed as economic } \\
\text { problems and given 'price tag'. } \\
\text { World governed by competitiveness and the struggle } \\
\text { for dominance and survival (dependence on resource } \\
\text { imports framed as a threat; weak concern with the } \\
\text { global impacts. } \\
\text { Ambiguity: Predominantly economic frames, but also } \\
\text { implicit deep ecological and civilizational concerns (e.g. } \\
\text { deaths due pollution, animal deaths and food waste } \\
\text { due to unsustainable food consumption patterns). }\end{array}$ \\
\hline 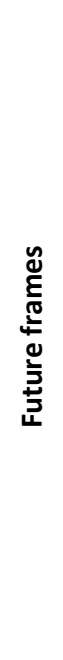 & $\begin{array}{l}\text { Scenarios of } \\
\text { change } \\
\text { (transition } \\
\text { process) }\end{array}$ & $\begin{array}{l}\text { Policies to correct resource pricing and } \\
\text { support innovative technologies } \\
\text { Companies to change their practices by } \\
\text { introducing innovative technologies in } \\
\text { response to market incentives } \\
\text { Consumers to change their behaviour in } \\
\text { response to price signals }\end{array}$ & $\begin{array}{l}\text { Projections of cost savings and wider } \\
\text { economic gains from resource efficiency } \\
\text { (growth and jobs) } \\
\text { Estimates of financing needed for improving } \\
\text { resource efficiency } \\
\text { Estimates of potential resource savings due } \\
\text { to technological innovation } \\
\text { Resource productivity (a relative measure of } \\
\text { decoupling) as the main indictor of progress }\end{array}$ & $\begin{array}{l}\text { Timely, predictable and controlled } \\
\text { transformation to allow for developing wealth } \\
\text { and wellbeing, whilst reducing the levels and } \\
\text { impact of our resource use. } \\
\text { Policy framework to shape economy and } \\
\text { lifestyles by providing 'right' incentives. } \\
\text { Market prices as the primary guide for } \\
\text { purchasing choices and investment decisions } \\
\text { Reducing information asymmetry to boost } \\
\text { innovation and open new markets, and guide } \\
\text { consumption decisions. } \\
\text { Indicators to open up new sources of } \\
\text { sustainable growth and strengthen } \\
\text { competitiveness. }\end{array}$ & $\begin{array}{l}\text { Assumption of rational behaviour of economic actors } \\
\text { and consumers. Mechanistic perception of change } \\
\text { mechanisms. } \\
\text { Belief in humankind's ingenuity. Humankind can } \\
\text { 'orchestrate' the planet. Assumption of scientific and } \\
\text { technological breakthroughs. } \\
\text { Economic transition is to lead to radically changed } \\
\text { consumer behaviour and wider understanding about } \\
\text { interface between economic and nature. } \\
\text { Stronger global perspective (shift from Euro-centric } \\
\text { perspective in setting problem frames). } \\
\text { The vision frames are stronger about the need to } \\
\text { protect nature and recognise planetary limits. } \\
\text { Ambiguity: Call for the 'fundamental transformation' of } \\
\text { behaviour while embracing values underlying current } \\
\text { consumption-based economic model. }\end{array}$ \\
\hline
\end{tabular}




\subsection{Narrative coherence of the Roadmap}

The narrative coherence can be analysed within one policy narrative (internal coherence) or in comparison to other narratives (external coherence). Internal narrative coherence focuses on a logical consistency between historical and prospective causal assumptions in a policy narrative, and a frame coherence across analytical layers within a policy narrative. External narrative coherence is based on a comparative analysis of a policy narrative framework with other relevant policy narrative frameworks. Comparative narrative analysis can point to similarities, differences or ambiguities related to specific components and layers of policy frames.

A comparative approach to frame analysis is key for analysis and resolution of policy controversies as originally postulated by Schön and Rein (1994). First, pointing to differences or divergences between narratives is directly relevant to analysing explicit or potential policy controversies. Second, spotting ambiguities or gaps in policy narratives is relevant to revealing discursive spaces (or issues) where future controversies, leading to conflicts or alignments, may emerge. Ambiguities and gaps may point to elements of policy frames that are 'under construction' where new arguments, meanings and positions are being constructed and negotiated. These are particularly relevant for observing changes in frames and reframing. By distinguishing between historical and prospective policy narratives POLiFRAME adds another dimension to the analysis allowing for comparing different temporal elements of policy narratives (see Figure 7).

\subsubsection{Internal narrative coherence}

The overall Roadmap's narrative was intended to be internally coherent in terms of argumentation. The overall approach was to reconcile the frames of economic growth and progress with the frames of planetary boundaries. The narrative coherence was to be ensured by reframing the environmental concerns and translating them into economic language of opportunity and threat. This was based on an assumption that the rationallyacting policy makers and economic actors can design and implement a win-win transition that delivers economic and environmental benefits. The turn towards an economic narrative could indeed result in an internally coherent narrative. However, an analysis of internal coherence reveals areas of ambiguity and an implicit internal conflict.

Majority of the Roadmap's text suggests it is deeply rooted in the dominant values of the neo-liberal growth-oriented model built on the belief in the rational progress based on human ingenuity and technology. In this worldview:

- Nature is symbolically reduced to an economically exploitable factor - a commodity which does not include other types of value and implicitly implies substitutability of nature with other inputs of similar economic value;

- The stance towards absolute decoupling is weak (consequence of the above);

- The relations between humankind and nature is hierarchical where the latter is to serve the former;

- The concern with the global impacts is vague, which undermines the planetary dimension of resource flows and associated environmental presses and reveals the overriding concern with the economic competitiveness of Europe. 
In contrast to the above, the Roadmap's future vision calls for the systemic change of natural resource management practices and for the 'fundamental transformation' of behaviour and consumption recognising 'planetary boundaries'. The reductionist view on the mechanisms of social change emerging from other sections of the document does not align with the vision. The notion of 'fundamental transformation' requires a deeper reflection on the transition process absent in the document. The analysis of internal coherence of the Roadmap, notably comparing historical and future dimensions of the narrative, revealed conflicting statements and ambiguities in framing of the document. This inconsistency reflected diverging views within the EC, and within DG Environment, on how to frame resource efficiency at the time of drafting the document (Miedzinski 2015).

\subsubsection{External narrative coherence of the Roadmap's narrative}

In order to position the narrative of the EC Roadmap in the wider EU discourse the study constructed aggregate narratives - or meta-narratives - of resource efficiency. Metanarratives were constructed based on recurring storylines and argumentations emerging in the EU public discourse. First, recurring arguments and claims in storylines as expressed by the interviewed stakeholders were mapped onto the POLiFRAME timeline (Figure 7).

\section{Figure 7. Recurring arguments and claims in resource efficiency narratives ${ }^{3}$}

\section{Arguments and claims}

\begin{tabular}{|c|c|c|}
\hline \multirow[t]{2}{*}{ 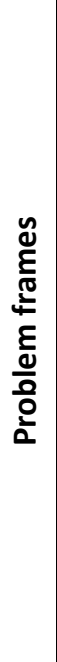 } & $\begin{array}{l}\text { Systemic } \\
\text { deficiencies }\end{array}$ & $\begin{array}{l}\text { Underlying assumption: earth's natural resources are abundant / earth's resources } \\
\text { have absolute limits } \\
\text { Lack of access to resources (political and economic problem) / Resource intensive } \\
\text { technologies, products, services as well as production processes and infrastructures / } \\
\text { Deficiency in the current economic model / Deficiency in the social and value systems } \\
\text { Path-dependency created by the current model (e.g. structural and institutional lock- } \\
\text { ins) } \\
\text { Global trends: population growth, economic growth in the developing world leading } \\
\text { to higher demand for resources (neo-Malthusian argument) }\end{array}$ \\
\hline & $\begin{array}{l}\text { First-order } \\
\text { problems }\end{array}$ & $\begin{array}{l}\text { High prices of commodities } \\
\text { Limited access to resources (scarcity) } \\
\text { High environmental pressures and impacts } \\
\text { Dependency on imported materials as a threat to competitiveness } \\
\text { Excessive consumption and mismanagement of natural resources }\end{array}$ \\
\hline \multirow{2}{*}{ 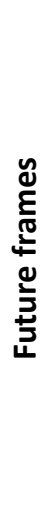 } & $\begin{array}{l}\text { Scenarios of } \\
\text { change }\end{array}$ & $\begin{array}{l}\text { Ensuring access to resources / Changing production and consumption models } \\
\text { Innovate technologies to get access to resources / Innovate production process and } \\
\text { products / Innovative business models / Innovate systems } \\
\text { Policy to provide incentives for a desired pathway: intervention from encouraging } \\
\text { efficiency to imposing absolute limits; instruments: market-based solutions, } \\
\text { command and control, research and innovation, education and changing behaviour }\end{array}$ \\
\hline & $\begin{array}{l}\text { Future } \\
\text { vision }\end{array}$ & $\begin{array}{l}\text { Material growth / dematerialised growth / de-growth } \\
\text { Adapted current economic model / new economic models / new social and cultural } \\
\text { systems } \\
\text { Humankind exploits nature efficiently / Humankind and nature part of the same } \\
\text { system (the Gaian vision) }\end{array}$ \\
\hline
\end{tabular}

\footnotetext{
${ }^{3}$ Based on 42 stakeholder interviews conducted in May-June 2012 (Stakeholder interview 2012).
} 
Second, the qualitative analysis of the excerpts singled out two critical dimensions of resource efficiency narratives that differentiated various approaches:

- Problem boundaries (from production system to cultural and value system) and

- Dominant rationales of intervention (from access to resources to resource sufficiency).

Overlaying these two dimensions allowed for constructing four stylised meta-narratives: Resource-intensive economy, Material-efficient economy, Circular economy and Sufficiency economy (Figure 8). Aggregating narratives allowed to structure a seemingly chaotic discursive space into a stylised narrative landscape 'surrounding' the Roadmap, and to compare how its narrative aligned or diverged from other narratives.

\section{Figure 8. Mapping meta-narratives of resource efficiency}

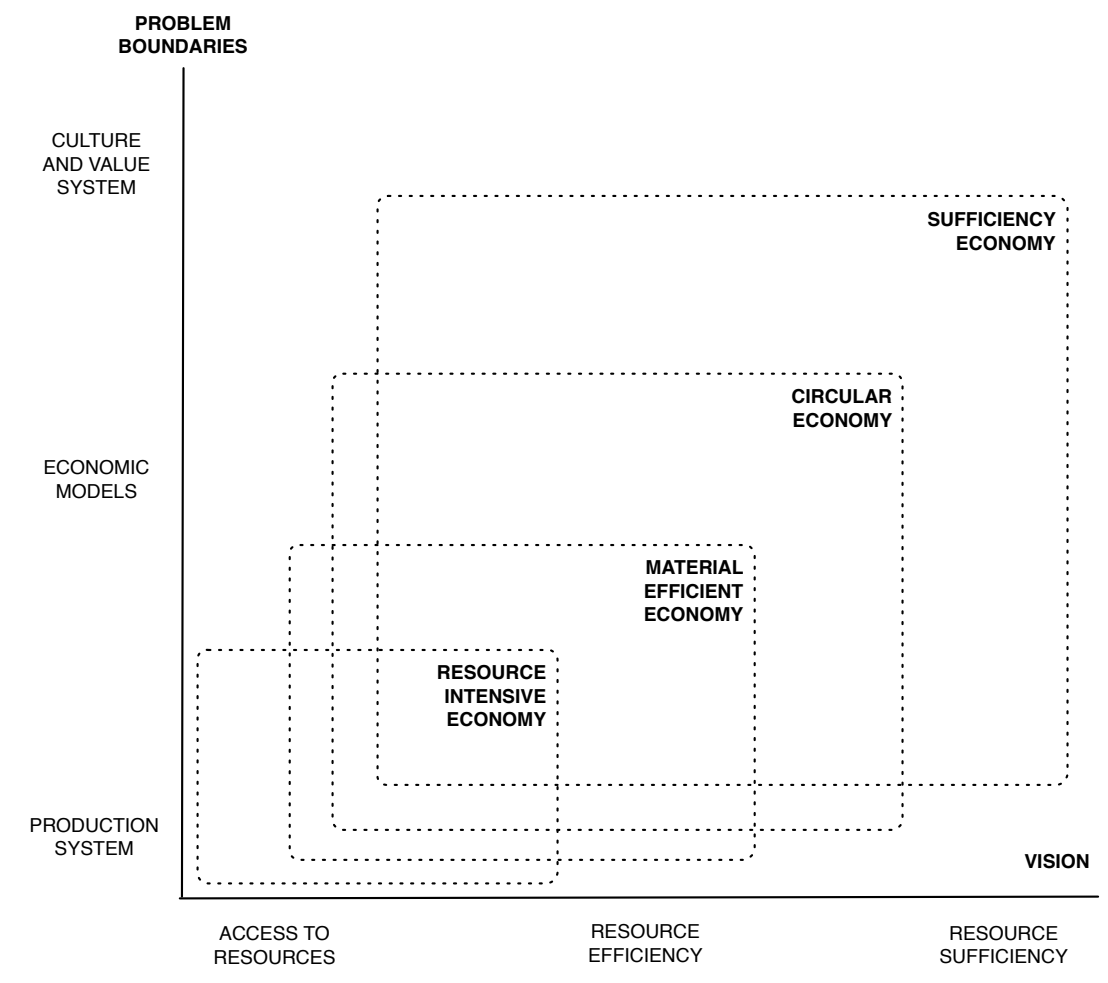

The Roadmap resonates in different ways with all the meta-narratives (Figure 9). In terms of perception of the first-order problems, most storylines align in pointing to economic problems of high prices of commodities and the prospect of material scarcity as the most burning resource-related issues. These predominantly economic frames were influenced by the post-crisis political climate at the time of research that favoured growth-related argumentation (Miedzinski 2015). Only the Sufficiency economy meta-narrative saw the excessive consumption itself as the a systemic underlying problem.

The analysis of systemic deficiencies reveals more fundamental differences. The Roadmap diverges from the Resource-intensive economy narrative built around the issue of access to primary materials. The Roadmap points to market and policy failures as key systemic problems of the current economic model that leads to unsustainable use of resources. This understanding is close to the Circular economy narrative, although the latter has a lesser focus on the policy failure and concentrates more on suggesting changes to the economic and business models. The Roadmap calls for more sustainable consumption 
patterns and changes in consumer behaviour, but approaches the behavioural change as a rational process that can be predictably changed by providing right economic incentives and information. The narrative of Sufficiency economy has a different approach recognising other drivers of behavioural change such as belonging to community and the recognition of inherent value of nature.

Analysing underlying assumptions on the relationship between humankind and nature reveals fundamentally different worldviews behind various narratives. The relation varies from hierarchical relationship, in which humankind is superior and separate from nature, to the other extreme, in which humanity and nature are part of one system. The Roadmap appears to be firmly rooted in the hierarchical worldview, in which humanity and nature are considered separate and the nature is subordinate to human progress. The perspective of mutual respect between humans and nature, and valuing nature for its non-economic value (as in sufficiency economy) is absent from the narrative.

Why is analysing policy narrative coherence important? The lack of internal narrative coherence may be a result of logical flaws and knowledge gaps but it also may reflect more fundamental disagreements and diverging worldviews. Analysing internal narrative coherence helps to find inconsistencies and ambiguities in policy documents and positions. This may well help to identify and resolve inconsistencies, or even open policy debates on issues previously not on the policy agenda.

An analysis of external narrative coherence may in some cases explain internal inconsistencies. What appears as an internally inconsistent policy document, for example, may in fact be a result of an instrumental strategy and explicit choice of policy actors. Policy narratives may be purposefully ambiguous to appeal to different powerful groups holding different views on a topic or simply because consensus on the problem has not yet been reached.

A critical policy analyst should keep in mind that, depending on the political context and timing, policy makers may be more concerned with aligning with diverse viewpoints and not antagonising relevant actors, thus sacrificing consistency and clarity of messaging, rather than with constructing an internally coherent narrative. See section 4.6 for the short discussion on external coherence of the Roadmap. 
Figure 9. External coherence: comparing the Roadmap narrative to resource efficiency meta-narratives

\begin{tabular}{|c|c|c|c|c|c|c|}
\hline & & EC RE Roadmap & Resource-intensive economy & Material-efficient economy & Circular economy & Sufficiency economy \\
\hline \multirow{2}{*}{ 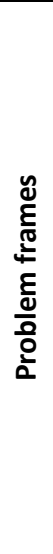 } & $\begin{array}{l}\text { Systemic } \\
\text { deficiencies }\end{array}$ & $\begin{array}{l}\text { Similarities: Economic systems based on the } \\
\text { linear model of unsustainable resource-intensive } \\
\text { growth (circular economy) } \\
\text { Differences: Regulation as a historical barrier to } \\
\text { access resources (resource-intensive economy) } \\
\text { Ambiguity: Unsustainable consumption-based } \\
\text { culture (sufficiency economy) }\end{array}$ & $\begin{array}{l}\text { Environmental protection is too } \\
\text { stringent given extraction } \\
\text { technologies are clean and safe. } \\
\text { Technologies not sufficiently } \\
\text { developed to extract resources. } \\
\text { Population growth and economic } \\
\text { development in emerging economies }\end{array}$ & $\begin{array}{l}\text { Production systems based on the } \\
\text { inefficient model of material- } \\
\text { intensive processes and products } \\
\text { Inefficient infrastructures, } \\
\text { technologies, products as well as } \\
\text { business models } \\
\text { Population growth and economic } \\
\text { growth in emerging economies }\end{array}$ & $\begin{array}{l}\text { Economic systems based on the } \\
\text { linear model of unsustainable } \\
\text { resource-intensive growth } \\
\text { Mismanaged material flows, } \\
\text { business models and value } \\
\text { chains, badly designed products } \\
\text { Population growth and economic } \\
\text { growth in emerging economies }\end{array}$ & $\begin{array}{l}\text { Social and economic systems } \\
\text { based on the model of } \\
\text { unsustainable growth and } \\
\text { consumption-based culture. } \\
\text { Market has failed to account for } \\
\text { negative environmental effects. } \\
\text { Population growth and economic } \\
\text { growth in emerging economies }\end{array}$ \\
\hline & $\begin{array}{l}\text { First-order } \\
\text { problems }\end{array}$ & $\begin{array}{l}\text { Similarities: High prices of resources (all } \\
\text { narratives but sufficiency economy), } \\
\text { environmental impacts (all) } \\
\text { Differences: Regulation as a barrier to access } \\
\text { (resource-intensive economy) } \\
\text { Ambiguity: Excessive consumption only related } \\
\text { to food waste and land (sufficiency economy) }\end{array}$ & $\begin{array}{l}\text { High prices of resources } \\
\text { Dependency on imported materials } \\
\text { Difficult access to natural resources } \\
\text { (e.g. regulatory framework) } \\
\text { Key resources available mainly in } \\
\text { developing and emerging countries }\end{array}$ & $\begin{array}{l}\text { High prices of resources } \\
\text { High share of material cost } \\
\text { Low material productivity } \\
\text { Dependency on imported } \\
\text { materials } \\
\text { Environmental impacts }\end{array}$ & $\begin{array}{l}\text { High prices of resources } \\
\text { Waste streams } \\
\text { Environmental impacts } \\
\text { Dependency on imported } \\
\text { materials } \\
\text { Difficult access to resources }\end{array}$ & $\begin{array}{l}\text { Excessive consumption } \\
\text { Waste streams } \\
\text { Environmental impacts }\end{array}$ \\
\hline \multirow{2}{*}{ 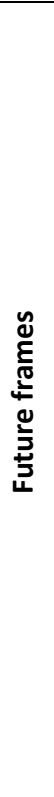 } & $\begin{array}{l}\text { Scenarios of } \\
\text { change }\end{array}$ & $\begin{array}{l}\text { Similarities: Policies to correct resource pricing } \\
\text { and support innovative technologies (material- } \\
\text { efficient and circular economy) } \\
\text { Differences: Social innovation to support } \\
\text { sustainable lifestyles and limited consumption } \\
\text { (sufficiency economy); policies to impose } \\
\text { absolute targets (sufficiency economy) proposed } \\
\text { in relation to land } \\
\text { Gap: The lack of reflection on alternative } \\
\text { transition pathways and different types of } \\
\text { innovation (circular and sufficiency economy) }\end{array}$ & $\begin{array}{l}\text { Better access to materials: Need to } \\
\text { innovate technologies to get access } \\
\text { to so far unexplored resources and } \\
\text { territories. } \\
\text { Policies to support better access to } \\
\text { resources and frame economic } \\
\text { relations with resource-rich countries } \\
\text { to allow access to resources. } \\
\text { Secondary and renewable resources } \\
\text { an alternative but in a longer term. }\end{array}$ & $\begin{array}{l}\text { More productive use of } \\
\text { materials: Mix of incremental } \\
\text { (but widely diffused) and radical } \\
\text { technological and non- } \\
\text { technological innovations } \\
\text { More radical innovations } \\
\text { substituting critical materials } \\
\text { Policies to support development } \\
\text { and diffusion of innovative } \\
\text { technologies and to influence } \\
\text { resource pricing }\end{array}$ & $\begin{array}{l}\text { Circular use (re-use, recycling, up } \\
\text { cycling) of resources: system } \\
\text { innovation to support } \\
\text { performance-oriented business } \\
\text { models and closed-loop systems } \\
\text { of production and consumption } \\
\text { (need for both technological and } \\
\text { non-technological innovations). } \\
\text { Policies to support system } \\
\text { innovation and to influence } \\
\text { resource pricing }\end{array}$ & $\begin{array}{l}\text { Strong sustainability in use of } \\
\text { resources: social innovation to } \\
\text { support sustainable lifestyles and } \\
\text { limited consumption. } \\
\text { System innovation to support } \\
\text { performance-oriented business } \\
\text { models and closed-loop systems. } \\
\text { Policies (including quotas, targets } \\
\text { and pricing) to protect nature } \\
\text { and support resource-efficient } \\
\text { social and system innovation }\end{array}$ \\
\hline & Future vision & $\begin{array}{l}\text { Similarities: Economy and society re-organised } \\
\text { to close the loops of material flows (circular } \\
\text { economy) } \\
\text { Differences: Material growth and high } \\
\text { consumption (resource-intensive economy) } \\
\text { Ambiguity: Vision leans towards the notion of } \\
\text { absolute decoupling; radical 'behavioural } \\
\text { change' will imply changing consumption } \\
\text { patterns but unclear in what way } \\
\text { Gap: Reflection on alternative social and } \\
\text { economic models (sufficiency economy) }\end{array}$ & $\begin{array}{l}\text { Technology-based economy and } \\
\text { society. Technological innovation } \\
\text { ensures that problems related to } \\
\text { access to resources are resolved. } \\
\text { Benefits from efficient extraction } \\
\text { allow to withstand competition and } \\
\text { to test alternative technologies. } \\
\text { Material growth and high } \\
\text { consumption. }\end{array}$ & $\begin{array}{l}\text { Technology-based economy } \\
\text { society. Technological and non- } \\
\text { technological innovations ensure } \\
\text { that problems related to } \\
\text { inefficient use of resources are } \\
\text { resolved. } \\
\text { Relative decoupling and growth } \\
\text { thanks to high material } \\
\text { productivity }\end{array}$ & $\begin{array}{l}\text { Economy and society re- } \\
\text { organised to close the loops of } \\
\text { material flow. Technological and } \\
\text { non-technological innovations } \\
\text { ensure that problems are } \\
\text { resolved. } \\
\text { Absolute decoupling and growth } \\
\text { thanks to system innovation. }\end{array}$ & $\begin{array}{l}\text { Humanity uses resources only } \\
\text { when needed to satisfy human } \\
\text { needs. } \\
\text { Key role of local decentralised } \\
\text { economic and social models } \\
\text { based on self-sufficiency. } \\
\text { Absolute decoupling and steady } \\
\text { state economy. }\end{array}$ \\
\hline
\end{tabular}




\subsection{Reframing of the $E U$ resource policy narrative}

The section discusses the reframing of resource policy narrative from the historical perspective by comparing the Roadmap (as a part of EU2020 package) to the pre-existing resource efficiency policy frame introduced by the 2005 EU Thematic Strategy. Both documents addressed the challenge of unsustainable production and consumption patterns that lead to - or are likely to cause future - environmental impacts. They both recognise economic implications and opportunities of improved 'resource efficiency' in the Roadmap and 'eco-efficiency' in the Thematic Strategy. The global dimension of problem, and the dependency of European economies on renewable and non-renewable materials originating outside the EU are emphasised in both documents.

While neither document questions economic growth as an overall objective of EU policy, the documents revealed different understanding of the scope of resource efficiency, notably in relation to the economic and business dimension of the challenge. The Thematic Strategy approaches resource efficiency mainly from the point of view of reducing environmental impacts of economic growth. The Roadmap frames the challenge of resource efficiency as a win-win strategy, and places a far greater emphasis on an economic and business opportunity of resource efficiency. The Roadmap's narrative is explicit about the need of a systemic change referring to new economic models such as circular economy. This is a significant step-up of ambition compared to the Thematic Strategy of 2005, signalling an attempt of radical reframing of the scope of the challenge. The challenge is not anymore mainly about reducing information asymmetry by improving metrics. It attempts to place resource efficiency at a centre of a major socio-economic transition redefining current economic system and business models.

Similarly, the Roadmap has a more ambitious policy outlook than the Thematic Strategy. The Strategy concentrated on developing precise metrics and evidence base in order to better focus policy action and to ensure the most cost efficient implementation of environmental protection measures for public authorities and economic operators (CEC 2005). The strategy had an ambition to integrate 'environmental concerns' into other policy fields mainly through developing an 'analytical framework' that allows for factoring in environmental concerns into public policies. The Roadmap explicitly admits that the traditional environmental policy failed to meet a systemic challenge of resource efficiency. It calls for a radical rethinking of environmental policy arguing that it also needs to offer positive incentives to enable the societal transition to a more resource efficient economy and society. This reveals a vision of a new generation of environmental policy that is no longer preoccupied mainly with environmental protection but also offers positive instruments to steer economic and industrial transformation.

Another symbolic difference is an explicit recognition of the concept of planetary boundaries in the Roadmap. The 2005 Thematic Strategy recognised the unsustainable patterns of resource consumption and stated that the continuation of the current trends would lead to significant impacts. At the same time, however, it played down the impacts of scarcity, indicating that the market mechanisms and technology advancement have provided an answer to the supply problems in the past. The Roadmap, on the other hand, recognises that scarcity of some resources (notably water and land take) have or may imminently lead to problems that the market and technology alone will not solve. The document frames increasing waste generation of some waste streams as a problem. The 
document extends the scope of the challenge by including passages on the damage of ecosystem services caused by resource use and by harmful emissions (notably air pollution and GHG emissions). Despite these differences in scoping the challenge, both documents rely on a similar underlying worldview. Neither document questions the economic growth as a basis of an economic model. Both documents are rooted in the rationalistic worldview based on an assumption of rational behaviour of economic agents and policy actors foreseeably reacting to policy and market incentives.

\subsection{Roadmap as a part of the reframing of EU environmental policy 4}

Resource efficiency became a key political priority for DG Environment in early 2010 when the new Commission started its term. The initial frames of the challenge were set by Europe 2020 strategy (CEC 2010) that positioned resource efficiency as an economic issue and set the overall objective of decoupling. As several interviewed EU policy makers argued, from the political point of view, 'resource efficiency' appeared easier to adapt as a part of the new post-crisis recovery frames than climate change or any other environment-related issue. Resource efficiency as a positive pro-growth policy agenda was to resonate with business and economic decision makers.

The phrase 'resource efficiency' was selected as it did have a history within DG Environment, notably as one of the central themes of the 2005 Thematic Strategy. As interviewed EC officials explained, the challenge DG Environment faced was to construct a consistent policy narrative around the new issue that would sufficiently reflect the past work of the DG, resonate with DGs responsible for economic policies (notably DG Enterprise) as well as to exploit the opportunity to position environmental policy at the centre of the EU strategy in a new guise.

The reframing was perceived as a major challenge by policy makers and EC officials. 'The golden age of environmental policy is over' as one of the officials put it. The new focus on economic rationale of resource efficiency meant moving out from the comfort zone of a traditional environmental policy. Interviewed policy stakeholders argued we could witness a shift from a traditional model of environmental policy focused on environmental protection and nature conservation towards a policy addressing relations between economy and environment. This new policy focused on, using the words of one EC official, the 'anthropogenic dimension that is relations between humans and economy and environment' and asked 'how to change economy?'. In the new frame, the political focus of environmental policy was to change from regulating economic actors towards improving the underlying economic model. Interviewed policy officials saw the need for this shift to both assure that environmental policy stays 'in the political game' as well as to attempt deeper changes in the rationale and scope of environmental policy. Testimonies from highly-ranked EC officials confirmed that emphasis on economic frames of resource efficiency was intentional and targeted at economic actors both within the EC (notably DG Enterprise) and outside the institution (especially economic ministries in Member States).

Changing the policy frames also implied an ambition to enlarge its traditional portfolio of policy measures deployed by environmental policy (from regulatory towards market-based

\footnotetext{
${ }^{4}$ This section is based on 42 stakeholder interviews conducted in May-June 2012. The claims in the sections are based on the stakehoder interviews unless otherwise stated. For an extended empirical case study on reframing illustrated with citations please consult Miedzinski (2015).
} 
measures and supply side instruments). The policy was expected to change its approach and attitude towards economic actors. The thinking behind the Roadmap was that reframed environmental policy should rely more on the positive economic incentives rather than on the regulatory pressure traditionally associated with environmental policy. Using the language of economic opportunity was, therefore, an explicit strategy of DG Environment, notably of the cabinet. Officials argued that economic argumentation would give the narrative 'higher profile and more credibility'. This was an opportunistic and admittedly risky strategy supported by highly-ranked environmental policy makers to give 'a new boost' to the sustainability agenda.

The stakeholder interviews pointed to many internal hurdles the reframing faced within the EC. Internal discussions and consultations revealed different understandings and policy visions of resource efficiency within the DG as well as between the DG and the Cabinet, which - according to several officials - have not been resolved during the drafting process. The internal debate was full of tensions and included parallel, often heated, discussions on the overall problem and future frames of resource efficiency (environmental versus economic narrative), on the specific implications of the agenda for sub-areas traditionally dealt with by DG Environment (e.g. what does it mean for waste management, air pollution etc.) as well as on the role and way of approaching other DGs. The process was not supported by 'learning environment' favourable of social learning and change (Argyris and Schon, 1996).

The lack of internal consensus within the EC and the contentious internal consultations can partially explain overly generic and not fully coherent narrative of the Roadmap. As the EC officials at DG Environment knew that the resource efficiency would 'resonate differently with different groups', they kept it 'purposely vague' opening the possibility of many interpretations. The idea was that such an approach would work better to mobilise stakeholders rather than discourage them or risk negative mobilisation and backlash.

The Roadmap document became an 'intermediate product' purposefully drafted to accommodate different understandings and positions on resource efficiency and on the role of DG Environment in this emerging policy area. Thus beneath the dominant economic frame, the Roadmap reveals a rather complex set of framings characteristic for deep ecological frames (e.g. ethical concern with animal deaths caused by food waste).

\section{Discussion and next steps}

The article introduced and applied a novel conceptual framework and methodological approach to systematically map future-oriented policy narratives and critically reflect on policy frames. POLiFRAME allows for comparing historical and future theories of change emerging in policy discourse, and is particularly relevant in the context of future-oriented policies that aim at embracing long-term societal challenges.

The value and novelty of the framework is in combining concepts and analytical perspectives from different research traditions, including interpretive policy analysis, organisational learning, and critical futures studies. These combinations open several research avenues for future-oriented policy studies.

First, POLiFRAME emphasises the importance of temporal scope and different time frames of policy narratives. Policy narratives can be portrayed as timelines filled with the historical 
explanations of past trends side by side with arguments on likely or desired future developments. Taking into account the temporal focus of narratives makes it possible to study whether framing of policy arguments differ depending on their historical and future orientation, and how current and future problems are problematised by policy actors.

Second, with its emphasis on storylines and time frames, the framework allows to reconstruct and critically analyse explicit and implicit casual inferences made in policy narratives. This connects frame analysis with analysing theories of change (Argyris and Schon, 1996), and allows for studying internal temporal coherence of narratives by comparing causal assumptions underpinning their historical and prospective dimensions.

Third, the framework focuses on the use of evidence to support arguments in policy narratives. Importantly, POLiFRAME allows to analyse similarities and differences in selection and interpretation of evidence evoked to support historical and future-oriented lines of argumentation in the same policy narrative.

Last but not least, POLiFRAME combines policy narrative analysis from policy studies with the layered discursive analysis used in critical futures studies, notably the causal layered analysis (CLA) (Inayatullah, 1998). The design of analytical layers in POLiFRAME was inspired by CLA. The layers in POLiFRAME, however, are tailored to align with the temporal dimension of policy narratives, and to address research questions of the study on the use of evidence and causal inferences in future-oriented policy narratives.

POLiFRAME has been designed and tested as an analytical framework used to analyse any policy or strategic process with an explicit vision or future orientation. The framework is meant to be flexible and open for adaptations: both the analytical layers and the building block of the timeline can be adapted to specific questions and contexts. In terms of next steps, the framework should be further tested and elaborated by introducing comparisons between policy narratives evolving in different geographical and socio-cultural contexts, and by extending time horizons of empirical enquiry. Further research could aim at covering longer periods in its empirical analysis that would allow for repeating the fieldwork to gather new material from policy makers and other sources. This would permit a deeper reflection on the dynamics and effects of reframing across policy cycle.

POLiFRAME may find practical applications beyond policy analysis. In foresight, it could assist in scenario and vision building processes (e.g. as a companies of CLA). In policy design, the framework may be used to assist in constructing coherent theories of change underlying policy interventions. In policy evaluation, it could add interpretive depth to the analysis of the logic of intervention, notably in theory-based evaluation and impact assessments (IA). The process of designing and analysing alternative policy options in the ex-ante IAs, for example, could benefit from developing policy narrative frameworks underlying considered policy options. This would allow for assessing the potential of various options to align with the position of key policy stakeholders. Finally, with its focus on narrative coherence the framework may be useful for non-governmental initiatives and movements seeking more coherent framing for their messaging ${ }^{5}$.

\footnotetext{
${ }^{5}$ See Lakoff's call for coherent framing of social movement in Lakoff (2010).
} 


\section{References}

1. Argyris, Chris and Donald A. Schon (1996), Organizational learning II : theory, method, and practice, (Organization development series, New York: AddisonWesley) xvi, 305.

2. Carbonell, Javier, Antonio Sanchez-Esguevillas, and Belen Carro (2016), 'The role of metaphors in the development of technologies. The case of the artificial intelligence', Futures SI: Metaphors in FS, 84 145-53.

3. CEC (2005), 'Thematic Strategy on the Sustainable Use of Natural Resources', $\operatorname{COM}(2005), 670$

4. -- - (2010), 'Europe 2020, A Strategy for Smart, Sustainable and Inclusive Growth. Communication from the Commission', $\operatorname{COM}(2010), 2020$

5. - - - (2011a), 'Roadmap to a Resource Efficient Europe. Communication from the Commission', $\operatorname{COM}(2011), 571$

6. - - - (2011b), 'A Resource-Efficient Europe-Flagship initiative under the Europe 2020 Strategy. Communication from the Commission', COM(2011), 21

7. Elkjaer, Bente (2003), 'Social learning theory: learning as participation in social process', in Easterby-Smith, Mark and Marjorie Lyles (eds.), Handbook of Organizational Learning and Knowledge Management (Blackwell Publishing),

8. Fischer, F. (2009), Democracy and expertise: Reorienting policy inquiry, (Oxford University Press).

9. Fischer, Frank and John Forester (1993), The Argumentative turn in policy analysis and planning, (Durham, N.C.; London: Duke University Press) viii, 327.

10. Fischer, Frank (2003), Reframing Public Policy. Discursive Politics and Deliberative Practices, (Oxford University Press).

11. Fischer, Frank, Gerald Miller, and Mara S. Sidney (2007), Handbook of public policy analysis : theory, politics, and methods, (Public administration and public policy ; 125, Boca Raton. FL: Taylor \& Francis) xxv, 642.

12. Fischer, Frank (2012), The argumentative turn revisited: Public policy as communicative practice, (Duke University Press).

13. Funtowicz, Silvio and Jerome R. Ravetz (1993), 'Science for the post-normal age', Futures, 25 (7), 739-55.

14. Goffman, Erving (1974), Frame Analysis. An Essay on the Organization of Experience, (Boston, Massachusetts: Northeastern University Press).

15. Guimarães Pereira, A, Rene Schomberg, and Silvio Funtowicz (2007), 'Foresight knowledge assessment', Journal of Foresight and Innovation Policy, 3 (1), 53-75.

16. Hajer, M. (1993), 'Discourse Coalitions and the Insitutionalisation of Practice: The Case of Acid Rain in Britain', in Fischer, Frank and John Forester (eds.), The Argumentative turn in policy analysis and planning (Durham, N.C.; London: Duke University Press), viii, 327. 
17. Hajer, Maarten A. and H. Wagenaar (2003), Deliberative policy analysis: understanding governance in the network society, (Theories of institutional design, Cambridge, UK ; New York, USA: Cambridge University Press) xv, 307.

18. Inayatullah, Sohail (1998), 'Causal layered analysis: Poststructuralism as method', Futures, 30 (8), 815-29.

19. Inayatullah, Sohail, et al. (2016), 'Metaphors in futures research', Futures SI: Metaphors in FS, 84, Part B 109-14.

20. Judge, Anthony (2016), 'Metaphor as fundamental to future discourse', Futures SI: Metaphors in FS, 84, Part B 115-19.

21. Lakoff, G. and Mark Johnson (1980), Metaphors we live by, (Chicago: The University of Chicago Press).

22. Majone, Giandomenico (1989), Evidence, Argument, and Persuasion in the Policy Process, (Yale University Press).

23. Miedzinski, Michal (2015), 'Public policy for long-term societal challenges? The reframing of policy narratives and the Roadmap to a Resource Efficient Europe', (University of Manchester).

24. Rockström, J., et al. (2009), 'A safe operating space for humanity', Nature, 461472 75.

25. Schomberg, René von, Ângela Guimarães Pereira Pereira, A, and Silvio Funtowicz (2005), 'Deliberating Foresight Knowledge for Policy and Foresight Knowledge Assessment',

26. Schon, Donald A. and Martin Rein (1994), Frame reflection: Toward the resolution of intractable policy controversies, .

27. Vallis, R. and S. Inayatullah (2016), 'Policy metaphors: From the tuberculosis crusade to the obesity apocalypse', Futures, 84 133-44.

28. van Eeten, Michel (2007), 'Narrative Policy Analysis', in Fischer, Frank, Gerald Miller, and Mara Sidney (eds.), Handbook of Public Policy Analysis. Theory, Politics, and Methods (CRC Publishers),

29. Wenger, Etienne (1998), Communities of practice : learning, meaning, and identity, (Learning in doing. social, cognitive, and computational perspectives, Cambridge: Cambridge University Press) xv, 318. 